\title{
CORRESPONDENCE
}

\section{Measurement of ras p21 in the urine of people occupationally exposed to chromium compounds}

Editor-Some chromium compounds have been assessed to be carcinogenic from both epidemiology and animal exposure studies. The carcinogenicity of chromium seems to be exclusively associated with some of the largely insoluble hexavalent chromium compounds that have been shown to induce tumours in rodents at the site of injection. ${ }^{2}$ In humans, the tissues primarily affected by exposure to chromium compounds are the nasal passages and the lungs. ${ }^{3}$ Two mechanisms of chromate genotoxicity have been proposed. The first of these centres around the production of direct damage to DNA by an intermediate pentavalent chromium species combined with DNA-protein crosslinks caused by trivalent chromium, the end product of biological chromate reduction. ${ }^{4}$ The second mechanism involves a combination of the oxidation of DNA by hexavalent chromium resulting in DNA strand breaks and the subsequent binding of the trivalent chromium generated during these reactions. ${ }^{5}$ These forms of DNA damage could result in the activation of specific cellular oncogenes including the Kirsten-ras (K-ras) oncogene that has been reported to be one of the multiple molecular changes involved in the development of human lung cancer. ${ }^{6}$ Measurement of the ras oncogene product (ras p21) in plasma has previously been proposed as a method for predicting an increased risk of developing an occupationally induced malignancy. ${ }^{7}$ Ras p21, which is present in the general circulation will, because of its low molecular weight (21 000), be freely filtered by the kidney and excreted in urine, offering another sampling medium for the analysis of extracellular ras p21.

We have developed an immunoblotting method for the measurement of ras p21 in urine and validated it with urine samples associated with either bladder or prostate cancer. ${ }^{8}$ This method can measure both total urinary ras p21, and detect mutationally activated forms of ras p21 that are thought to contribute to the development of some malignancies including bladder cancer $^{9}$ and lung cancer. ${ }^{6}$ We have used this method to analyse spot (random, untimed) urine samples obtained from cohorts with either occupational exposure to chromium $(n=10)$ or no occupational exposure to chromium $(n=30)$. The exposed group were process operators in a plant involved in the preparation of chromium compounds from chromite ore. The geometric mean urinary chromium concentration in these groups was $18.19 \mathrm{nmol} / \mathrm{mmol}$ creatinine $(95 \%$ confidence interval $(95 \% \mathrm{CI}) 9 \cdot 45-35 \cdot 06)$ and $0.63 \mathrm{nmol} / \mathrm{mmol}$ creatinine $(95 \% \mathrm{CI}$ $0.40-1.01)$, respectively. The geometric mean concentrations of urinary ras p21 in the groups exposed and unexposed to chromium was $963 \mathrm{ng} / 1 \quad(95 \% \quad \mathrm{CI}$ $357-2602)$ and $896 \mathrm{ng} / 1 \quad(95 \% \quad \mathrm{CI}$ 426-1884), respectively. Although the mean urinary chromium concentration in the exposed group was significantly higher $(P<0.0001)$ than that of the unexposed group, the mean urinary ras p21 concentrations in the two groups were indistinguishable. More importantly, none of the urine samples associated with chromium exposure contained the mutationally altered forms of ras p21 that have been associated with the development and progression of malignant disease.

$$
\begin{array}{r}
\text { A E SCOBBIE } \\
\text { Health and Safety Laboratory, } \\
\text { Broad Lane, } \\
\text { Sheffield S3 7HQ } \\
\text { T C AW } \\
\text { Institute of Occupational Health, } \\
\text { University of Birmingham, } \\
\text { Edgbaston, } \\
\text { Birmingham B15 } 2 T T
\end{array}
$$

1 Chromium, nickel and welding. IARC Mono Eval Carcinog Risks Hum 1990;49:1-648.

2 Katz SA, Salem H. The toxicology of chromi-
Kal Carcinog Risks Hum 1990;49:1-648. um with respect to its chemical speciation: a review. F Appl Toxicol 1993;13:217-24.

3 Langard S, Norseth T. Chromium. In Friberg L, Norberg GF, Vouk VB, eds. Handbook on the toxicology of metals. Amsterdam: Elsevier, 1986:202-5.

4 Beyersmann D. Biochemical speciation of chromium in genotoxicity. Toxicology and Environmental Chemistry 1989;22:61-7

5 Bronzetti G, Galli A. Influence of NTA on genotoxicity. Toxicology and Environmental genotoxicity. Toxicology and

6 Gazdar AF. The molecular and cellular basis of human lung cancer. Anticancer Res 1994; 14:261-7.

7 Brandt-Rauf PW, Niman HL, Smith SJ. Correlation between serum oncogene expression and the development of neoplastic disease in a worker exposed to carcinogens. F R Soc Med 1990;83:594-5.

8 Scobbie AE, Anderson JB, Horwich A. Detection of activated ras p21 in urine samples associated with bladder and prostate ples associated with bladder and

9 Jones RF, Debiec-Rychter M, Wang CY. Chemical carcinogenesis of the urinary bladder-a status report. $\mathcal{F}$ Cancer Res Clin Oncol 1992;118:411-9.

\section{Offspring sex ratios as an index of pollution hazard in residential environ- ments}

Editor,-Williams et al ${ }^{1}$ chose 12 localities with exposure to pollution from a variety of industrial sources, and 12 nearby control localities without such exposure. The standardised mortality ratios for all causes and for lung cancer were significantly higher in the polluted localities than in the controls. In contrast, the sex ratios of offspring were not consistently or significantly affected in one direction or the other. These authors concluded that "monitoring of the sex ratio does not provide a reliable screening measure for detecting cryptic health hazards from industrial air pollution in the general residential environment". This may seem puzzling in view of the evidence (that they cite) that pollution affects offspring sex ratios. I should like to offer a possible explanation.

There is some evidence that stress causes parents to produce children of the sex opposite to that of the stressed parent. The point may be illustrated by the sex ratios of the offspring of male and female patients with multiple sclerosis (MS). ${ }^{2}$ Offspring conceived before the onset of disease have normal sex ratios. But offspring born to female patients after the onset of disease have a non-significant male excess, and those sired by male patients after the onset of disease have a significant female excess. These two sex ratios are significantly different $\left(\chi^{2}=6.5, P \bumpeq 0.01\right)$.

It seems that although MS is not known to be an endocrine disease, these sex ratios are hormonal effects of it. This argument is supported by the finding that the adrenals are larger in patients with MS than in controls, ${ }^{3}$ which suggests that patients' adrenocorticotrophic hormone concentrations are high. This would be expected to lead to high concentrations of testosterone in women, and low concentrations in men. ${ }^{4}$ Thus according to a hypothesis for which a great deal of evidence now exists, ${ }^{5}$ this would explain the excess of male offspring born to female patients, and the excess of female offspring born to male patients.

I suggest that the sex ratios of offspring of patients with MS may be instructive in the search for effects of pollution on sex ratio.

Multiple sclerosis is a terrible affliction: its diagnosis is frequently uncertain, so patients and physicians are not sure what is wrong. In many cases, relapses and remissions alternate. There is no established treatment: alternative treatments flourish while patients remit-only to be followed by relapse and despair. Some of the same sort of stress is offered by polluted environments. The immediate unpleasantness of industrial air pollution is compounded with the uncertainty of (and suspicions concerning) its consequences for health.

If there is anything in the analogy, then pollution may have opposite effects on the sex ratios of offspring of exposed fathers and mothers. If that were so, these effects may mask one another: and this would explain the failure to detect effects of air pollution on the sex ratio in residential environments (where parents of both sexes are exposed). Attempts to detect such effects should concentrate on the sex ratios of offspring of exposed fathers with unexposed mothers and vice versa.

WH JAMES The Galton Laboratory, Department of Genetics and Biometry, University College London, Wolfson House, 4 Stephenson Way,
London NW1 $2 H E$

1 Williams FLR, Ogston SA, Lloyd OL. Sex ratios of births, mortality, and air pollution: can measuring the sex ratios of births help to identify health hazards from air pollution in industrial environments? Occup Environ Med 1995;52:164-9.

2 James WH. Sex ratios of the offspring of patients with multiple sclerosis. Neuropatients with multiple Scler
epidemiology 1994;13:216-9.

3 Reder AT, Makowiec RL, Lowy MT. Adrenal size is increased in multiple sclerosis. Arch
s. size is increased in muld
Neurol $1994 ; 51: 151-4$.

4 Kemper TD. Social structure and testosterone. London: Rutgers University Press, 1990 137

5 James WH. The human sex ratio. Part 2: a hypothesis and a program of research. Hum Biol 1987;59:873-900. 